\title{
Fluconazole-Beta-Cyclodextrin Inclusion Complexes. Preparation and Characterization in Solid State
}

\author{
ANDRADA IFTODE ${ }^{1 \#, ~ R O X A N A ~ R A C O V I C E A N U ~}{ }^{1 \#, ~ R A Z V A N ~ S U S A N ~}{ }^{2 \#,}$ \\ DANIELA MARTI ${ }^{3 \#}$, IULIA PINZARU ${ }^{1 *}$, RADU LAZAU ${ }^{4 *}$, MONICA SUSAN $^{2}$, \\ ALEXANDRA GHEORGHISOR ${ }^{1}$, CODRUTA SOICA ${ }^{1}$, CRISTINA TRANDAFIRESCU $^{1}$ \\ 1"Victor Babes" University of Medicine and Pharmacy, Faculty of Pharmacy, ${ }^{\text {nd }}$ Eftimie Murgu Sq., 300041, Timisoara, \\ Romania \\ 2"Victor Babes" University of Medicine and Pharmacy, Faculty of Medicine, $2^{\text {nd }}$ Eftimie Murgu Sq., 300041, Timisoara, \\ Romania \\ ${ }^{3}$ Western University Vasile Goldis Arad, 94 Revolutiei Blvd., 310025, Arad, Romania \\ ${ }^{4}$ Politehnica University Timisoara, ${ }^{\text {nd }}$ Victoriei Sq., 300006, Timisoara, Romania
}

Abstract: Fluconazole is a bistriazole derivative with antifungal activity. The major weak points of fluconazole are the development of antifungal resistance and low water solubility, which impairs its administration. Binary systems between fluconazole and beta-cyclodextrin were prepared with the aim of obtaining a new delivery system that will overcome the limitations of fluconazole administration. Using two feasible laboratory methods, inclusion complexes between fluconazole and betacyclodextrin were obtained. Thermal and spectroscopic analyses were used to characterize the inclusion complexes.

Keywords: fluconazole, beta-cyclodextrin, inclusion complex

\section{Introduction}

Fluconazole (2-(2,4-difluorophenyl)-1,3-bis(1,2,4-triazol-1-yl)propan-2-ol, IUPAC), is a bistriazole derivative with antifungal activity (Figure 1) [1].

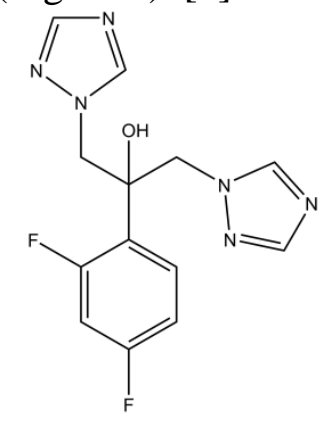

Figure 1. Structural formula of fluconazole

Fluconazole (FLU) is a fungistatic agent being predominantly active against Candida species, Cryptooccus neoformans, Histoplasma, Blastomyces and Coccidioides species. Fluconazole is mainly indicated for the treatment and prophylaxis of disseminated and deep organ candidiasis in both normal and immune compromised patients and is considered the agent of choice for the treatment of cryptococcal meningitis and for prophylaxis of cryptococcosis in AIDS patients. Fluconazole has shown only weak activity against Aspergillus species [2-4]. 
Fluconazole has a very good oral bioavailability which is not influenced by the gastrointestinal $p \mathrm{H}$ or by the presence of food [1]. The drug is widely distributed into organism and penetrates the bloodbrain barrier. The elimination long-life of FLU is ranging from 27 to $34 \mathrm{~h}$ and plasma protein binding is less than $10 \%$ [2]. The drug is excreted mainly unchanged in the urine, a small amount of it is excreted in the feces (10\%); the hepatic metabolism is negligible. Oral administration of FLU may cause gastrointestinal side effects, irritation and hepatotoxicity [5]. Fluconazole is administered orally and intravenously as a free base; $2 \mathrm{mg}$ of drug is dissolved in $1 \mathrm{~mL}$ of isotonic sodium chloride or $5 \%$ dextrose [2]. FLU is an interesting molecule being classified as belonging to two different BCS classes (class 1/3) [6] and it has structural flexibility, hydrophobic and hydrogen bonding capacity [7]. The structure of fluconazole contains two weak basic nitrogen rings linked to a propan-2-difluorophenyl-2ol chain, which gives the molecule hydrophobic properties and larger size. The molecule contains a propane chain enabling the rotation and twisting of the $\mathrm{C}-\mathrm{C}$ and $\mathrm{C}-\mathrm{N}$ bonds. The compound has poor water solubility, of only $1 \mathrm{mg} / \mathrm{L}$ (at room temperature), yet the 1,2,4-triazole rings give the molecule some hydrophilicity to balance the lipophilicity of the 2,4-difluorophenyl group [8].

Cyclodextrins (CDs) are macrocyclic oligosaccharides composed of $\alpha-(1,4)$ linked glucopyranose units, able to form host-guest complexes, through van der Waals forces, hydrophobic interactions and hydrogen bonding with various molecules including pharmaceutical substances [9-12]. Encapsulation of drugs by CDs may improve physico-chemical properties, such as water solubility, dispersibility, and bioavailability, which are desirable for obtaining pharmaceutical formulations with enhanced therapeutic effect $[13,14]$.

The potential of natural and chemically modified CDs to enhance the performances of biocides has been highlighted by researches in the field [15]. The use of cyclodextrins to improve bioavailability of drugs in pharmaceutical industry relies also on their favorable toxicity profile and biodegradability [16-18].

Beta-cyclodextrin, $\mathrm{C}_{42} \mathrm{H}_{70} \mathrm{O}_{35}$, (Figure 2) is a native water-soluble cyclodextrin comprising seven glucopyranose units, widely used in pharmaceutical research to improve drug properties due to its excellent ability to accommodate hydrophobic aromatic rings [8]. Fluconazole may accommodate into electron-rich hydrophobic cavity of a cyclodextrin due to its hydrophobic capacity represented by the aromatic rings. The three $\mathrm{sp}^{3}$ carbon atoms of the propane chain contribute to reduce the spatial hindrance and the proton of the hydroxyl group and the nitrogen atoms are donors/acceptors for hydrogen bonding interactions with the cyclodextrin [7].

Improving the dissolution properties of FLU by means of CD complexation may enhance its bioavailability and antifungal properties. The enhancement of water solubility of FLU by complexation with $\beta$-CD was reported by previous researches $[7,19,20]$.

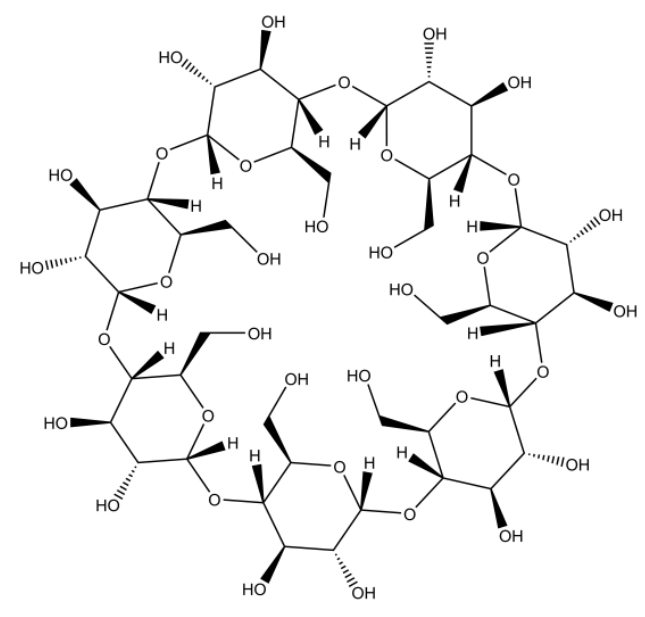

Figure 2. Structural formula of $\beta-C D$. 
Following these considerations, in this study we have proposed to investigate the obtaining and characterization of inclusion complexes between FLU and $\beta-C D$ in solid state, with the purpose of further investigation of improvement of solubility of FLU and of antifungal and antibiofilm properties of these inclusion complexes.

Inclusion complexes were obtained using two simple preparation methods, namely the physical mixture and the kneaded methods, in three molecular drug:CD ratio of 2:1, 1:1 and 1:2, respectively. Powder X-ray diffractometry (PXRD), Fourier transform infrared spectroscopy (FTIR) and differential scanning calorimetry (DSC) were used to characterize the interactions in solid state between the components of the supramolecular structure.

\section{Materials and Methods}

Fluconazole (M: $306.277 \mathrm{~g} / \mathrm{mol}$; water solubility: $1 \mathrm{mg} / \mathrm{L}$ ) was received from Gedeon Richter (Târgu Mures, Romania), $\beta$-cyclodextrin (M: $1135 \mathrm{~g} / \mathrm{mol}$ ) was purchased from Fluka (Sigma Aldrich Chemie, GmbH, Germany) and ethanol from Chimopar (Bucharest, Romania). All the reagents were of analytical grade and distilled water was used in all the experiments.

\section{Preparation of physical mixtures}

The physical mixtures (PMs) of FLU with $\beta$-CD were prepared in 2:1, 1:1 and 1:2 molar ratio. Exactly weighed amounts of FLU and $\beta$-CD were mixed in a mortar with a pestle until a homogeneous mixture was obtained.

\section{Preparation of kneaded products}

The kneaded products (KPs) of FLU with $\beta$-CD were prepared in 2:1, 1:1 and 1:2 molar ratio (FLU: $\beta$-CD). The active drug and $\beta-\mathrm{CD}$ were homogenized in a mortar with a pestle and a $50 \%(\mathrm{w} / \mathrm{w}$ ) aqueous ethanol solution was added corresponding to the molar ratio. The kneading process was continued until the whole solvent was evaporated. The resulting paste-like product was dried at $105^{\circ} \mathrm{C}$ until constant weight and then turned into a powder.

\section{Differential Scanning Calorimetry}

Differential scanning calorimetry was used to determine the thermal behavior of FLU, $\beta$-CD, the physical mixtures and the kneaded products. Measurements were assessed using a Mettler Toledo STAR Thermal Analysis System, DSC 821 (Mettler Inc., Schwerzenbach, Switzerland). Approximately 2-3 mg of active material or product was examined, in the following parameters: heating rate $-5^{\circ} \mathrm{C} / \mathrm{min}$, Ar flow rate $10 \mathrm{~L} / \mathrm{h}$, the temperature range $25-300^{\circ} \mathrm{C}$. X-ray Powder Diffractometry. The X-ray spectra were recorded using a Rigaku Ultima IV instrument operating at 40 $\mathrm{kV}$ and $40 \mathrm{~mA}, \mathrm{CuK} \alpha$ radiation.

\section{Fourier Transform Infrared Spectroscopy}

The FTIR spectra were recorded with a Shimadzu Prestige-21 spectrometer in the range 400-4000 $\mathrm{cm}^{-1}$ with a resolution of $4 \mathrm{~cm}^{-1}$. Was used the $\mathrm{KBr}$ pellet method.

\section{Results and discussions}

In order to obtain accurate information about the presumed formed inclusion complex, several analytical tools are used and their results are then, corroborated.

\section{Differential Scanning Calorimetry}

Differential scanning calorimetry represents a useful thermo-analytical method providing valuable information for the characterization of the inclusion complexes [14]. DSC is a reliable, simple and fast investigation method enabling the recognition of an inclusion complex and the characterization of its thermal stability [7]. The solid-state modifications observed for the inclusion complex are measured as 
a function of a controlled temperature program. Thermal curves of the host, guest and the inclusion complex are compared, generally searching for alteration of the peak area and /or shape, a shift of the melting point of the guest, an increase / decrease in the number of peaks of the guest $[14,21]$.

The thermo analytical characterization of FLU and $\beta-C D$ are represented in Figure 3.
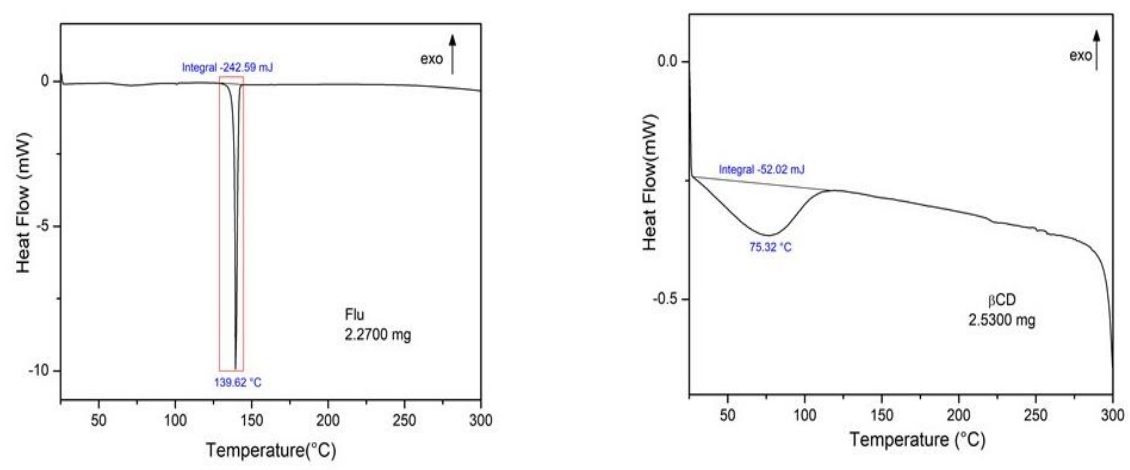

Figure 3. DSC curve for FLU and for $\beta-C D$

The FLU thermogram (Figure 3, left) shows a sharp endothermic peak at $139.62{ }^{\circ} \mathrm{C}$ which corresponds to the melting point of fluconazole, the obtained value being within the reported melting range $\left(138-140{ }^{\circ} \mathrm{C}\right)[7,22]$. The DSC curve of $\beta-\mathrm{CD}$ is characterized by a broadened endothermal effect ranging between $50-125^{\circ} \mathrm{C}$, with a maximum at $75.32{ }^{\circ} \mathrm{C}$, corresponding to its dehydration. The decomposition of the molecule takes place above $300{ }^{\circ} \mathrm{C}$, as can be notice from the Figure 3, right the shoulder-like form that suggest the beginning of this endothermic process.

The DSC thermograms of the PMs are presented in Figure 4.
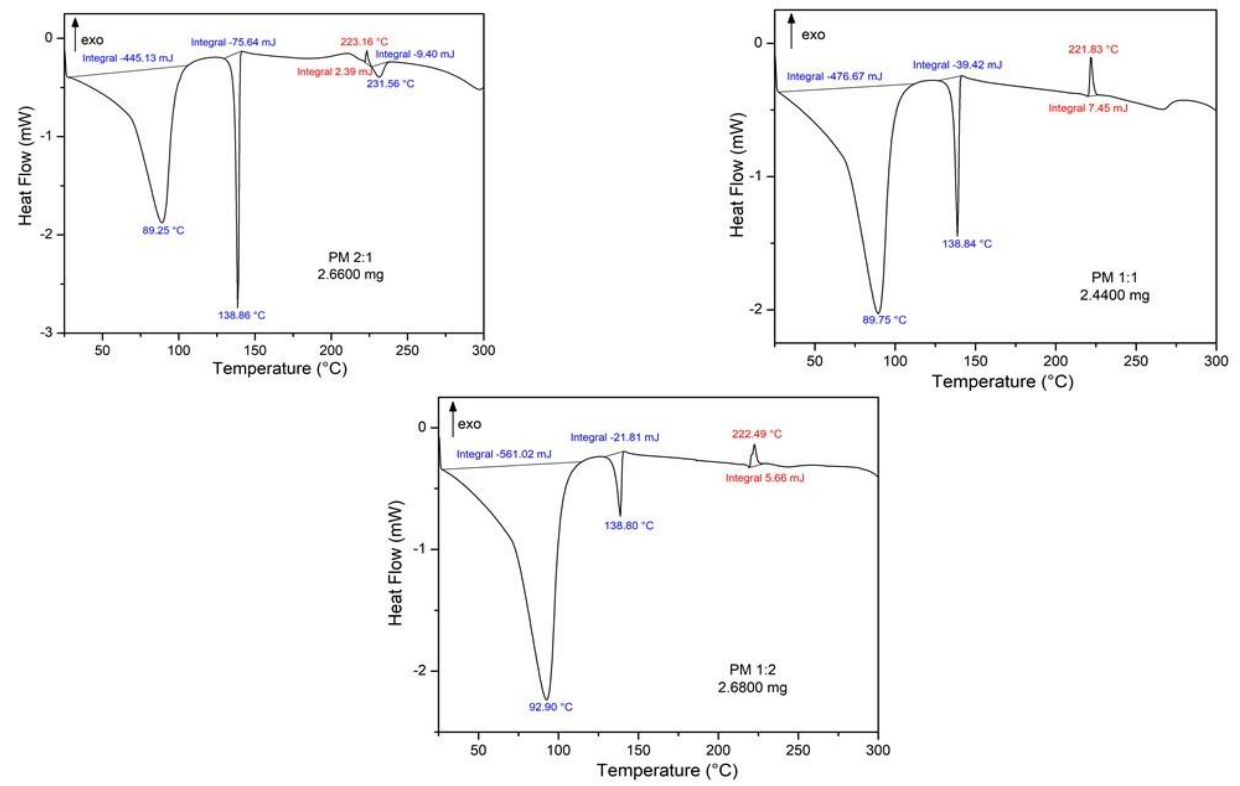

Figure 4. DSC curve for FLU- $\beta-C D$ physical mixture products

In the case of the physical mixtures, the characteristic peaks of FLU are evidenced. Around $90 \pm 1{ }^{\circ} \mathrm{C}$ one can notice a sharp endothermic peak representing the dehydration of the $\beta$-CD. The second significant endothermic effect is located around $138{ }^{\circ} \mathrm{C}$ and is attributed to the melting of FLU. The intensity of the recorded endothermic effect varies according to the molar ratios used between the two components. The small exothermic effect located around $220{ }^{\circ} \mathrm{C}$, present on all the curves may be due to the crystallization of an intermediary compound formed in the mixing process. 
The thermograms of the kneaded products are presented in Figure 5.

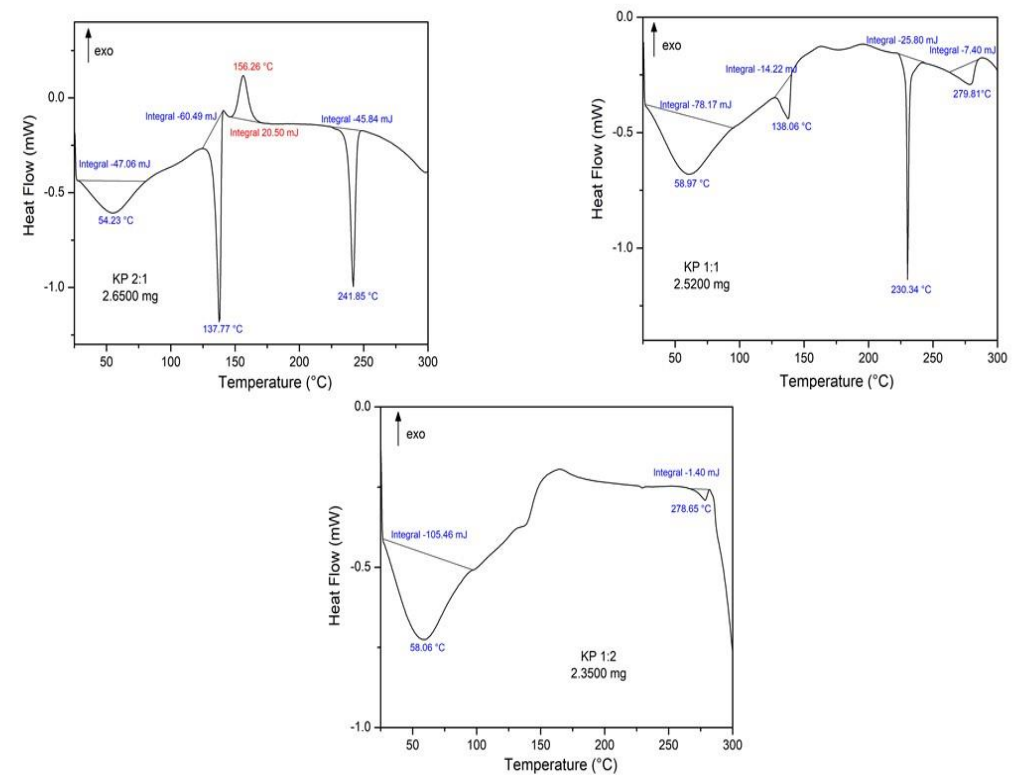

Figure 5. DSC curve for FLU- $\beta$-CD kneaded products

All the DSC curves recorded for the kneaded samples presented an endothermic effect around $56 \pm 2{ }^{\circ} \mathrm{C}$, which is justified by the water removal. In the case of the KP $2: 1$, one can notice several effects: the endothermic effect located at $137.77^{\circ} \mathrm{C}$ represents the melting of FLU, the exothermic effect at $156.26^{\circ} \mathrm{C}$ can be attributed to the crystallization of the newly formed inclusion complex, the endothermic effect located at $241.85^{\circ} \mathrm{C}$ is due to the melting of the newly formed entity; after $250^{\circ} \mathrm{C}$ it can be observed another endothermic effect linked to the thermal decomposition. In the case of KP 1:1 (Fig. 5), at $138^{\circ} \mathrm{C}$ is evidenced a small endothermic peak, characteristic for the melting of the FLU; a sharp endothermic peak located at $230.34{ }^{\circ} \mathrm{C}$ indicates the melting of the formed inclusion complex, further decomposed at $279.81^{\circ} \mathrm{C}$. For the KP 1:2 (Figure 5), around the specific thermal range for FLU melting, no endothermic effect was recorded, suggesting an amorphisation process/ inclusion complex formation. Due to the high amount of cyclodextrin, only a small endothermic effect is noticed at $278.65{ }^{\circ} \mathrm{C}$, representing the decomposition.

\section{Powder X-ray diffractometry}

Powder X-ray diffractometry is a non-invasive technique used to determine the identity of a substance and the crystallinity degree or amorphization. The information obtained from PXRD is very often used to ascertain the results obtained from DSC analysis. The analysis consists in comparison of diffractograms of pure components with the diffractogram of the presumed inclusion complex. The shifting / changes of the characteristic peaks of the guest are considered indicative of the formation of a new solid form $[23,24]$.

PXRD patterns of FLU, $\beta-C D$ and their binary systems are shown in Figure 6. 


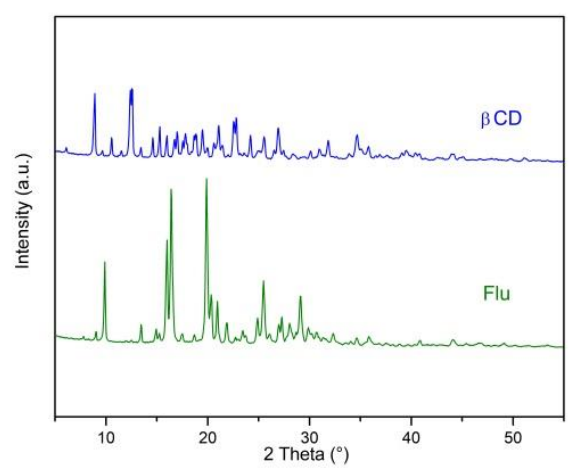

Figure 6. PXR diffractograms of FLU and $\beta-C D$

In the diffractogram of FLU one can notice several distinct diffraction peaks, attributable to its crystalline structure at 9.9, 16.00, 19.0 and 20.0 degrees $(2 \theta)$.

The diffractogram of $\beta-C D$ revealed the characteristic peaks of a crystalline material. The diffraction patterns of FLU and $\beta-\mathrm{CD}$ are in good agreement with those obtained by Li et al [7].

Figures 7 and 8 present the PXRD patterns of PM and KPs

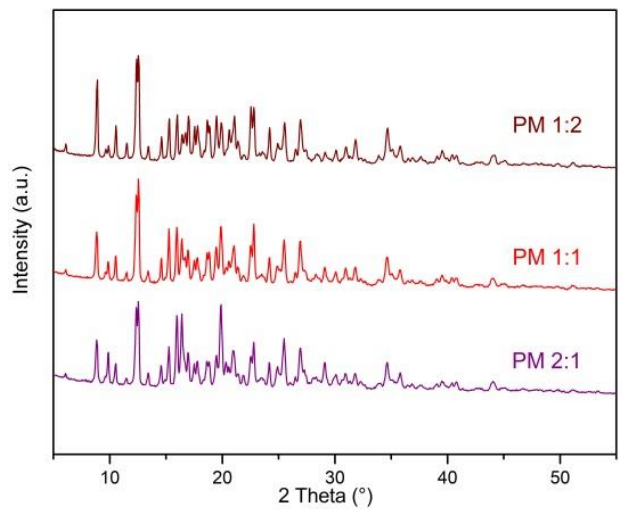

Figure 7. PXR diffractograms of the FLU- $\beta$-CD physical mixtures

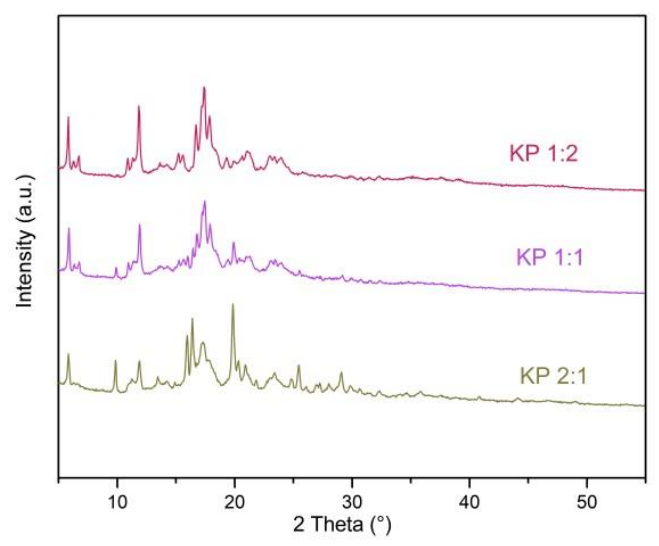

Figure 8. PXR diffractograms of the FLU- $\beta-C D$ kneaded products 
The X-ray spectra of each inclusion compound did not represent the superimposed spectra of FLU and $\beta-C D$, indicative of an inclusion/amorphisation process.

The PXRD patterns of PMs reveales the presence of the characteristic peaks of FLU, in addition to the $\beta$-CD peaks, with reduced intensities. A significant difference was observed in the X-ray patterns of KPs as compared to those of individual materials. The disappearance / the marked reduction of intensity of FLU characteristic peaks suggests a strong interaction between the FLU and $\beta-C D$.

Moreover, one can notice a greater degree of amorphization as compared to the PM products.

These results are in good agreement with the DSC analysis which clearly indicated, the formation of a new distinct compound.

\section{Fourier Transform Infrared Spectroscopy}

Fourier-transform infrared spectroscopy represents a valuable complementary technique for identification of inclusion complexes. As in previously described techniques, spectra of the guest, host and inclusion complex are compared, searching for alteration in the guest spectrum, due to modification of the environment around the guest molecule, as a consequence of inclusion. Changes in the characteristic bands of the guest molecule: disappearance, broadening, modification of peak intensity, shifts in their wave number support the inclusion [25].

The spectra of FLU and $\beta-C D$ are presented in Figure 9.

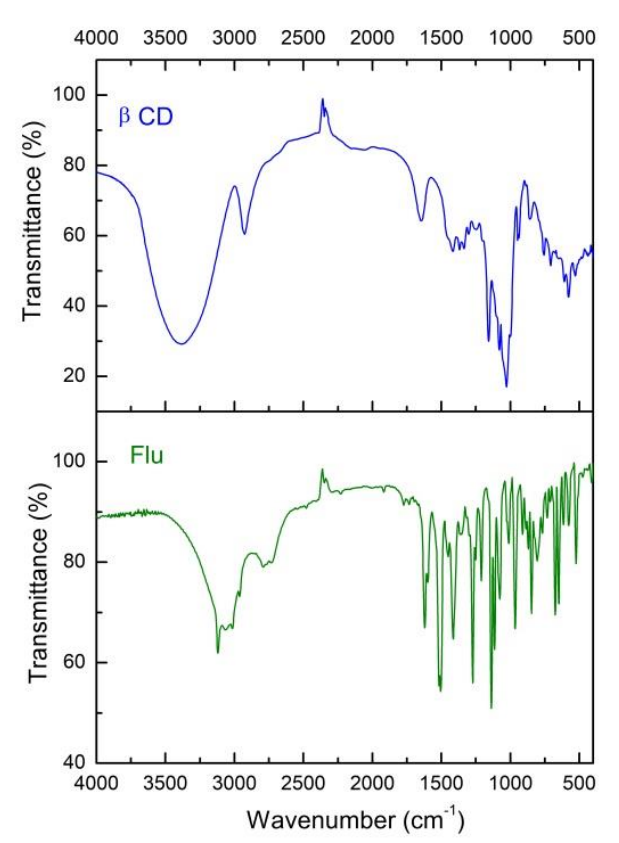

Figure 9. FTIR spectra of FLU and $\beta-C D$

The FT-IR spectrum of FLU is characterized by the presence of the vibrational bands located at: 1620 and $1514 \mathrm{~cm}^{-1}$ attributed to $\mathrm{C}=\mathrm{C}$ stretch aromatic ring; at 1502 and $1417 \mathrm{~cm}^{-1}$ due to triazole ring stretch; at $1271 \mathrm{~cm}^{-1}$ for C-F stretch; at $1138 \mathrm{~cm}^{-1}$ for triazole ring breathing; at $1026 \mathrm{~cm}^{-1}$ for $\mathrm{C}-\mathrm{H}$ aromatic ring; at $960 \mathrm{~cm}^{-1}$ and $846 \mathrm{~cm}^{-1}$ for $\mathrm{C}-\mathrm{H}$ triazole ring. Also, one can notice the presence of a broad band in the range $3600-2500 \mathrm{~cm}^{-1}$ due to hydrogen bonded $\mathrm{O}-\mathrm{H}$ stretching vibrations. The results were similar to the results obtained by Klein Teleginski and co-workers [22].

The spectrum of $\beta-C D$ reveals a wide absorption band, at $1200-1000 \mathrm{~cm}^{-1}$, characteristic for the glucopyranosic ring and a broad $-\mathrm{OH}$ stretching absorption band in the $3000 \mathrm{~cm}^{-1}$ domain, in agreement with the results reported by Kelemen et al. [19].

The spectra of physical mixtures are presented in Figure 10. 


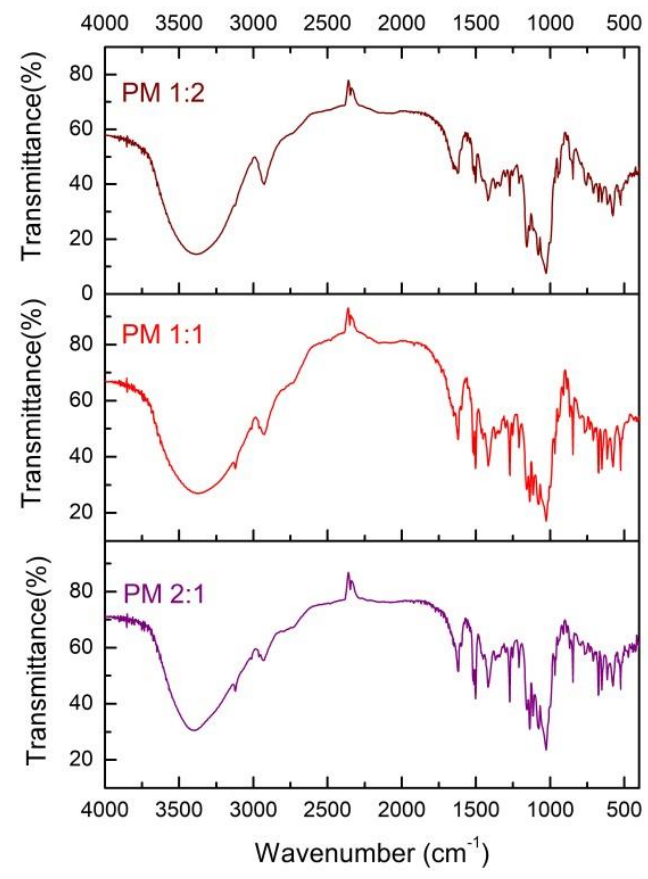

Figure 10. FTIR spectra of FLU- $\beta$-CD physical mixtures

In the absorption spectra of the PMs of FLU with $\beta$-CD one can notice the shifting / disappearance of some characteristic bands of FLU, namely, the shifting of the $1417 \mathrm{~cm}^{-1}$ band ( PM 2:1 and PM 1:2) and the $960 \mathrm{~cm}^{-1}$ band (PM 2:1), the disappearance of the $960 \mathrm{~cm}^{-1}$ band (PM 1:1, PM 1:2). Also, we noticed the shifting of the C-F stretching characteristic band at $1273 \mathrm{~cm}^{-1}$ for the PM 1:1.

The IR spectra of the KPs are shown in Figure 11.

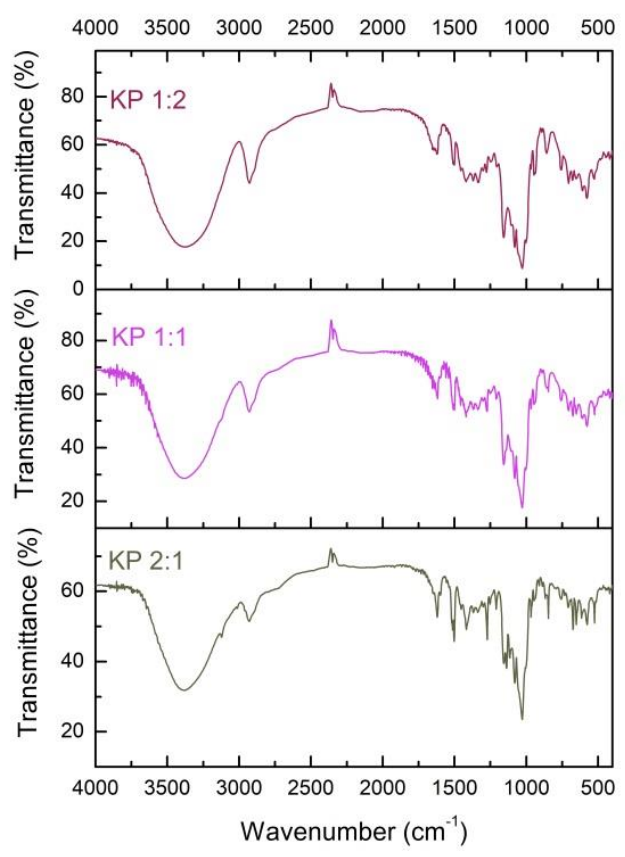

Figure 11. FTIR spectra of FLU- $\beta-C D$ kneaded products 
Analyzing the spectra of KPs, we observed for the $2: 1$ product, the shifting of the $960 \mathrm{~cm}^{-1}$ band, for the 1:1 product the shifting of the $1502 \mathrm{~cm}^{-1}$ and $1417 \mathrm{~cm}^{-1}$ bands and the disappearance of the bands at $1138 \mathrm{~cm}^{-1}$ and at $960 \mathrm{~cm}^{-1}$. For the $1: 2$ product, we observed the shifting of the $1502 \mathrm{~cm}^{-1}$, $1417 \mathrm{~cm}^{-1}$ and $1138 \mathrm{~cm}^{-1}$ bands and the disappearance of the $960 \mathrm{~cm}^{-1}$ and $846 \mathrm{~cm}^{-1}$ bands. One can also notice the shifting/disappearance of the C-F characteristic band at $1273 \mathrm{~cm}^{-1}$ for the KP $1: 1 / \mathrm{KP}$ $1: 2$.

Changes in FT-IR spectra of the inclusion complexes demonstrated the interaction between FLU and $\beta-\mathrm{CD}$, in all cases.

\section{Conclusions}

In this paper, we presented the obtaining and characterization in solid state of inclusion complexes between FLU and $\beta$-CD. The inclusion complexes were prepared using two feasible laboratory methods, namely physical mixture and kneaded method and the experimental techniques were DSC, PXRD and FTIR.

The DSC curves obtained for the PMs and the KPs were not a superposition of the DSC curves of the FLU and $\beta-\mathrm{CD}$, indicating a new molecular arrangement between the components. The best results in terms of amorphisation capacity of the CD were obtained for the KPs 1:1 and 1:2. The data obtained from the X-ray and FT-IR analyses, corroborated with the DSC results, confirmed the formation of a new solid product with different spectral and thermal properties in relation to the pure FLU and $\beta$-CD. Analyzing all the results, the FLU- $\beta$-CD inclusion complexes obtained by kneaded method in molar ratio of 1:1 and 1:2, with the greatest amorphisation degree and potential improved aqueous solubility, will be used for further antifungal and antibiofilm investigations.

\section{References}

1. GRIFFITH, R., Tracy T. Antifungal Drugs. In: Williams DA, Lemke TL, eds. Foye's Principles of Medicinal Chemistry. $5^{\text {th }}$ ed. Lippincott Williams \& Wilkins; 2002. p. 891-901.

2. BEALE, J., Anti-infective agents. In: Block J, Beale JM, eds. Wilson and Gisvold's Textbook of Organic Medicinal and Pharmaceutical Chemistry. $11^{\text {th }}$ ed. Lippincott Williams \& Wilkins; 2004. p. 217-281.

3. SHALINI, K., KUMAR, N., DRABU, S., SHARMA P.K., Advances in synthetic approach to antifungal activity of triazoles, Beilstein J. Org. Chem., 7, 2011, 668-677.

4. EMAMI, S., GHOBADI, E., SAEDNIA, S., HASHEMI, S.M., Current advances of triazole alcohols derived from fluconazole: Design, in vitro and in silico studies, Eur. J. Med. Chem., 170, 2019, 173194.

5. RENÇBER, S., KARAVANA, S.Y., YILMAZ, F.F., ERAÇ, B., NENNI, M., GURER-ORHAN, H., LIMONCU, M., H., GUNERI, P., ERTAN, G., Formulation and evaluation of fluconazole loaded oral strips for local treatment of oral candidiasis, J. Drug. Deliv. Sci. Technol., 49, 2019, 615-621.

6.BERGSTRÖM, C.A.S., ANDERSSON S.B.E, FAGERBERG, J.H., RAGNARSSON, G., LINDHAL A., Is the full potential of the biopharmaceutics classification system reached?, Eur. $J$. Pharm. Sci., 57, 2014, 224-231.

7. LI, J., ZHANG, S., ZHOU, Y., GUAN, S., ZHANG, L., J., Inclusion complexes of fluconazole with beta-cyclodextrin and 2-hydroxypropyl-beta-cyclodextrin in aqueous solution: preparation, characterization and a structural insight, Incl. Phenom. Macrocycl. Chem., 84, 2016, 209-217.

8. ORGOVAN, G., KELEMEN, H., NOSZAL, B., Protonation and beta-cyclodextrin complex formation equilibria of fluconazole, J. Incl. Phenom. Macrocycl. Chem., 84, 2016, 189-217.

9. FIFERE, A., MARANGOCI, N., MAIER, S., COROABA, A., MAFTEI, D., PINTEALA, M., Theoretical study on beta-cyclodextrin inclusion complexes with propiconazole and protonated propiconazole, Beilstein J. Org. Chem., 8, 2012, 2191-2201.

10. WENZ, G., Influence of intramolecular hydrogen bonds on the binding potential of methylated beta-cyclodextrin derivatives, Beilstein J. Org. Chem., 8, 2012, 1890-1895. 
11. QIU, N., LI, X., LIU, J., Application of cyclodextrins in cancer treatment, J. Incl. Phenom. Macrocycl. Chem., 89, 2017, 229-246.

12. HADARUGA, D., HADARUGA, N., BANDUR, G., RIVIS, A., COSTESCU, C., ORDODI, V., ARDELEAN, A., Berberis vulgaris extract/beta-cyclodextrin nanoparticles synthesis and characterization, Rev. Chem., 61, no. 7, 2010, 669-675.

13. KFOURY, M., LANDY, D., AUEZOVA, L., GREIGE-GERGES, H., FOURMENTIN, S., Effect of cyclodextrin complexation on phenylpropanoids solubility and antioxidant activity, Beilstein J. Org. Chem., 10, 2014, 2322-2331.

14. KELEMEN, H., CSIllaG, A., HANCU, G., SZEKELY-SZENTMIKLOS,I B., FULOP, I., VARGA, E., GRAMA, L., ORGOVÁN, G., Characterization of inclusion complexes between bifonazole and different cyclodextrins in solid and solution state, Maced J Chem Chem En., 36, no. 1, 2017, 81-91.

15. GALUSCAN, A., JUMANCA, D., BORCAN, F., SOICA, C., IONESCU, D., RUSU, L.C., ARDELEAN, L., CRAINICEANU, Z. Comparative study on polyurethane and cyclodextrin carriers for triclosan, Rev. Chem., 65, no. 2, 2014, 190-193.

16. NARDELLO-RATAJ, V., LECLERCQ L., Encapsulation of biocides by cyclodextrins: toward synergistic effects against pathogens, Beilstein J. Org. Chem., 10, 2014, 2603-2622.

17. POPA, G., DRAGOSTIN, O., DUMITRIU BUZIA, O., MITITELU TARTAU, L., PROFIRE, L., GAFITANU, C., Studies on obtaining and characterization a pregabalin-cyclodextrin complex for taste masking purpose, Rev. Chem., 68, no. 2, 2017, 337-340.

18. LECLERCQ, L., Interactions between cyclodextrins and cellular components: Towards greener medical applications?, Beilstein J. Org. Chem., 12, 2016, 2644-2662.

19. KELEMEN, H., HANCU, G., MENTES, B., FULOP, I., CARCU DOBRIN, M., MUNTEAN, D.L., MIRCIA, E. Characterization of inclusion complexes between fluconazole and different cyclodextrin derivatives, Rev. Chim., 70, (8), 2019, 2737

20. YURTDAS, G., DEMIREL, M., GENC, L., Inclusion complexes of fluconazole with betacyclodextrin: physicochemical characterization and in vitro evaluation of its formulations, J. Incl. Phen. Macrocycl. Chem., 70, 2011, 429-435.

21. ANTAL, D., ARDElEAN, F., PINZARU, I., BORCAN, F., LEDETI, I., CORICOVAC, D., ZUPKO, I., BAGHDIKIAN, B., OLLIVIER, E., SOICA, C., BOLINTINEANU, S., Effects of cyclodextrin complexation on the anti-cancer effects of Cotinus coggygria extract and its constituents, butein and sulfuretin, Rev. Chem., 67, (8), 2016, 1618-1622.

22. KLEIN TELEGINSKI, L., BIGGI MACIEL A., MENDES, C., SEGATTO SILVA, M.A., BERNARDI, L.S., DE OLIVEIRA P.R. Fluconazole-excipient compatibility studies as the first step in the development of a formulation candidate for biowaiver, J. Therm. Anal. Calorim., 120, 2015, 771781.

23. ROJAS-AGUIRRE, Y., YEPEZ-MULIA, L., CASTILLO, I., LOPEZ-VALLEJO, F., SORIAARTECHE, O., HERNANDEZ-CAMPOS, A., CASTILLO R., HERNANDEZ-LUIS, F., Studies on 6-chloro-5-(1-naphthyloxy)-2-(trifluoromethyl)-1H-benzimidazole/2-hydroxypropyl-beta-cyclodextrin association> Characterization, molecular modelling studies, and in vivo anthelminthic activity, Bioorg. Med. Chem., 19, 2011, 789-797.

24. SBARCEA, L., LEDETI, A., UDRESCU, L., VARUT, R-M., BARVINSCHI, P., VLASE, G., LEDETI, I., Betulonic acid-cyclodextrins inclusion complexes, J. Therm. Anal. Calorim., 138, no. 4, 2019, 2787-2797.

25. BRUSNIKINA, M., SILYUKOV, O., CHISLOV, M., VOLKOVA, T., PROSHIN A., MAZUR, A., TOLSTOY, P., TEREKHOVA, I., Effect of cyclodextrin complexation on solubility of novel antiAlzheimer 1,2,4-thiadiazole derivative, J. Therm. Anal. Calorim., 130, no. 1, 2017, 443-450.

$\overline{\text { Manuscript received: } 21.11 .2019}$ 